\title{
EXCITOTOXICIDADE GLUTAMATÉRGICA NA DOENÇA DE HUNTINGTON
}

\section{EXCITOTOXICITY GLUTAMATERGIC IN HUNTINGTON'S DISEASE}

\author{
Angelo Viana Weber, ${ }^{1}$ Luana Taís Hartmann Backes ${ }^{1}$ \\ ${ }^{1}$ Instituto Cenecista de Ensino Superior de Santo Ângelo - Iesa/Santo Ângelo /Brasil. \\ Autor correspondente: Angelo Viana Weber \\ e-mail: angelo.vw15@hotmail.com
}

\section{EDITORES}

Thiago Gomes Heck

(Unijuí-Brasil)

Adriane Cristina Bernat Kolankiewicz

(Unijuí-Brasil)

\section{EDITORES DE ÁREA}

Educação \& Saúde

Eva Teresinha de Oliveira Boff

(Unijuí-Brasil)

Fisioterapia \& Saúde

Eliane Roseli Winkelmann

(Unijuí-Brasil)

Ciências Farmacêuticas \& Saúde

Marilei Uecker Pletsch

(Unijuí-Brasil)

\section{Nutrição \& Saúde}

Lígia Beatriz Bento Franz

(Unijuí-Brasil)

Nadia Oliveira

(Unipampa-Brasil)

Ingrid Perry

(UNESC-Brasil)

Enfermagem e suas contribuições para a prática

Adriane Cristina Kolankiewicz

(Unijuí-Brasil)

Crhis de Brum

(UFFS-Brasil)

Neila de Souza

(UFSM-Brasil)

Exercício Físico \& Saúde

Thiago Gomes Heck

(Unijuí-Brasil)

Anderson Zampier Ulbrich

(UFPR)

\section{Editora Unijuí}

Universidade Regional do Noroeste do

Estado do Rio Grande do Sul (Unijuí)

\section{RESUMO}

O glutamato, por ser um dos aminoácidos mais abundante no sistema nervoso central (SNC), desempenha o papel de principal neurotransmissor excitatório. Dessa forma, a presente revisão busca avaliar a relação do glutamato no desenvolvimento da Doença de Huntington (DH) mediante o processo de excitotoxicidade, envolvendo o seu mecanismo de ação, receptores e transportadores glutamatérgicos associados. Para isso, realizou-se uma revisão da literatura nas bases de dados BVS, SciELO e Google Acadêmico. Foram separados 53 artigos e selecionados 25. Os demais artigos foram excluídos por não abordarem a temática pretendida. A DH é uma doença de poliglutaminas causada por uma mutação no gene codificador da proteína Huntingitna. A Huntingtina mutada irá promover uma série de alterações, desde a superestimulação dos receptores N-metil D-Aspartato (NMDA) até o comprometimento na regulação dos transportadores de glutamato 1 (GLT1), transportador de glutamato e aspartato (Glast) e baixos níveis de carreadores de aminoácidos excitatórios do subtipo 1 (EAAC1), desta forma conduzindo ao processo de neurodegeneração por meio da excitotoxicidade pelos níveis aumentados de glutamato. Deste modo, seria necessário atuar simultaneamente em todos os níveis da fisiopatologia para adquirir conhecimentos mais específicos nos mecanismos de neurodegeneração, sobretudo a excitotoxicidade pelo glutamato. Neste sentido, existe uma necessidade de realizar uma atuação mais direcionada aos níveis da fisiopatologia da $\mathrm{DH}$, a fim de adquirir novos conhecimentos específicos no que diz respeito a mecanismos de neurodegeneração, sobretudo a excitotoxicidade pelo glutamato.

Palavras-chave: Glutamato. Neurotransmissão Glutamatérgica. Doença de Huntington.

Submetido em: $1 \% 6 / 2016$

Aceito em: 27/10/2016 


\section{Revista}

\section{Contexto}

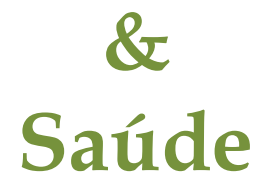

Volume 16

Número 31

2016

ISSN 2176-7114

A Revista Contexto \& Saúde é um periódico do Departamento de Ciências da Vida da Universidade Regional do Noroeste do Estado do Rio Grande do Sul (Unijuí). É um periódico semestral que tem por objetivo a divulgação da produção técnico-científica de temas relacionados à área de Ciências da Saúde.

O escopo da revista abrange a divulgação de resultados de pesquisa que contemplem avanços no processo saúde-doençacuidado e no conhecimento e aplicabilidade de novos processos químicos e biológicos em saúde.

Neste periódico, entende-se que a publicação de estudos com os aspectos epidemiológicos, assistenciais e educacionais em saúde, experimentais e aplicados é uma forma a subsidiar e qualificar a atenção à saúde de modo interdisciplinar.

\begin{abstract}
The glutamate as one of the most abundant amino acids in the central nervous system (CNS) plays the role of main excitatory neurotransmitter. Thus, this review is to evaluate the relationship glutamate in the development of Huntington's disease (HD) through the excitotoxic process involving its mechanism of action, receptors and associated glutamate transporters. For this, we carried out a review of the literature in the VHL databases SciELO and Google Scholar. They were separated 53 articles, and selected 25. The other articles were excluded for not addressing the desired theme. The DH is a polyglutamine disease caused by a mutation in the gene encoding the protein Huntingitna. The mutant Huntingtin will promote a number of changes since the overstimulation of N-methyl D-aspartate (NMDA) to the involvement in the regulation of glutamate transporters 1 (GLT1), glutamate transporter and aspartate (Glast) and low levels of carriers subtype of excitatory amino acids 1 (EAAC1). Thus leading to neurodegeneration process by excitotoxicity by increased levels of glutamate. Thus, it would be necessary to act simultaneously on all the pathophysiology of levels to acquire more expertise in neurodegeneration mechanisms, particularly excitotoxicity by glutamate. In this sense, there is a need for a more targeted action to the pathophysiology of $\mathrm{DH}$ levels, in order to acquire new specific knowledge regarding the mechanisms of neurodegeneration, especially by glutamate excitotoxicity.
\end{abstract}

Keywords: Glutamate. Glutamatergic neurotransmission. Huntington's Disease. 


\section{INTRODUÇÃO}

A Doença de Huntington (DH) é uma patologia autossômica dominante e monogênica. Além disso, é uma patologia poliglutamínica caracterizada por uma expansão da repetição CAG no gene HTT, a qual conduz à expressão de uma proteína chamada Huntingtina mutante (Httm) (RIBEIRO, 2014). A proteína mutante, por sua vez, caracteriza-se por deterioração motora progressiva, declínio cognitivo e perturbações psiquiátricas. Além de movimentos involuntários, arrítmicos e aleatórios (WALKER, 2007).

A Huntingtina mutante tem sido associada a vários mecanismos patológicos, incluindo a desregulação da transcrição, disfunção mitocondrial e estresse oxidativo, que poderá resultar na desregulação da função mitocondrial e/ou dos déficits de antioxidantes. A proteína afeta o sistema glutamatérgico de modo a estabilizar e aumentar a ativação de receptores N-metil D-Aspartato (NMDA) na superfície celular (RIBEIRO, 2014).

O glutamato, neste contexto, poderá funcionar como toxina poderosa quando presente em baixas ou altas concentrações, podendo fazer evoluir o quadro do paciente para algum transtorno neurodegenerativo. Para isso, torna-se importante saber os mecanismos de receptação do glutamato por neurônios e células gliais, determinando o tempo que o neurotransmissor estará disponível na sinapse (GREWER; RAUEN, 2005).

Desta maneira, o presente trabalho tem por objetivo avaliar a relação do glutamato no desenvolvimento da DH por meio do processo de excitotoxicidade, envolvendo o seu mecanismo de ação, receptores e transportadores glutamatérgicos, que, por sua vez, estejam associados a esta patologia.

\section{METODOLOGIA}

O estudo baseia-se em uma revisão bibliográfica conduzida em três etapas. Na primeira foram definidas as bases de dados Biblioteca Virtual em Saúde (BVS), Scientific Electronic Library Online (Scielo) e Google Acadêmico para a identificação dos artigos. A segunda etapa baseia-se na definição dos descritores inseridos na busca dos artigos e dos critérios de inclusão. Os termos utilizados na busca foram delimitados a partir das palavras-chave presentes em artigos adequados ao tema, lidos previamente de forma não sistemática. O uso dos descritores utilizados em conjunto para a identificação dos artigos foram os seguintes termos: Glutamato, Neurotransmissão Glutamatérgica, Doença de Huntington.

\section{RESULTADOS}

A busca de dados restringiu-se a artigos chaves/iniciais sobre os achados laboratoriais da DH publicados nas décadas de 70, 80 e 90. Além disso, artigos atualizados entre janeiro de 2001 e março de 2016, fazendo referência a dados encontrados em âmbito nacional e internacional. A consulta às bases de dados ocorreu entre janeiro e março de 2016. Os artigos selecionados passaram por uma análise de título, resumo e ano, para então refinar aqueles que estavam mais relacionados ao tema pesquisado. Após essa análise foram separados 53 artigos, os quais foram submetidos à leitura na íntegra, sendo selecionados 25 . Os demais, totalizando 28 , foram excluídos por não abordarem a temática pretendida nesta revisão.

\section{DISCUSSÃO}

\section{Síntese glutamatérgica}

O glutamato é um tipo de aminoácido que está presente de maneira mais abundante do sistema nervoso central (SNC), e suas funções metabólicas são basicamente idênticas às exercidas em outros tecidos, 
preponderantemente biossíntese de proteínas. Além disso, assume um importante papel, atuando como principal neurotransmissor excitatório. Outra função do glutamato é servir como um aminoácido constituinte da estrutura de proteínas, este também utilizado como energia nas células. Considera-se igualmente a sua participação no desenvolvimento neural, na plasticidade sináptica, no aprendizado, na memória, na epilepsia, na isquemia neural, na tolerância e na dependência a drogas, na dor neuropática, nos transtornos de ansiedade e na depressão (VALLI; SOBRINHO, 2014).

Este aminoácido não atravessa a barreira hematoencefálica, por isso deve ser sintetizado no tecido nervoso a partir de glicose e outros precursores. Uma das formas do glutamato ser sintetizado é através da via ciclo de Krebs e posterior transaminação do $\alpha$-cetoglutarato. Outra forma de produção de glutamato é por meio do ciclo de glutamato/glutamina que ocorre tanto nos neurônios quanto nas células gliais (CORONA; TAPIA, 2005; PINTO; RESENDE, 2014).

\section{Neurotransmissão glutamatérgica}

A neurotransmissão glutamatérgica decorre a partir da sua presença no citoplasma, de onde ele será transportado para o interior de vesículas sinápticas de glutamato através de um mecanismo dependente de gradiente próton-eletroquímico promovido por uma enzima chamada ATPase vacuolar. Após um estímulo despolarizante seguido pelo influxo de cálcio $(\mathrm{Ca} 2+)$, o glutamato vesicular é liberado na fenda sináptica. Uma vez liberado na fenda sináptica, o glutamato é captado pelas células gliais nas quais é convertido à glutamina pela enzima glutamina sintetase e posteriormente liberado por transportadores de glutamina no meio extracelular. A glutamina então é captada pelas células neuronais e reconvertida a glutamato. Para manter o equilíbrio e modular a função dos neurônios, existe também a liberação de glutamato pelas células gliais, além do mecanismo de reversão de transportadores que atua com a mesma função da liberação de glutamato, bem como a regulação (PINTO; RESENDE, 2014).

O glutamato presente no espaço extracelular possui pouca ou nenhuma conversão bioquímica, pois não há uma enzima que o degrade, como ocorre para muitos neurotransmissores. Deste modo, ele é capaz de interagir com os receptores até que se difunda ou seja removido do líquido extracelular por transportadores de aminoácidos excitatórios (EAATs). Os transportadores de glutamato, neste contexto, têm como função regular o tempo de concentração desse substrato na fenda sináptica (STROEH, 2008; GREWER; RAUEN, 2005; FEATHERSTONE, 2010).

Existem cinco tipos de EAATs, e cada um destes se difere em virtude de sua função e localização: transportador de aspartato-glutamato (GLAST/EAAT1), transportador de glutamato (GLT/EAAT2), transportador de aminoácido excitatório (EAAC/EAAT3), mais amplamente distribuídos no encéfalo, sendo encontrados em regiões não sinápticas, e os transportadores de aminoácidos excitatórios 4 e 5, que são encontrados respectivamente nas células de Purkinje e neurônios retinianos (EAAT4 e EAAT5). Os transportadores de aminoácidos excitatórios são importantes para a homeostase do glutamato extracelular, pois quando são farmacologicamente inibidos, seus níveis basais tendem a aumentar significativamente (FEATHERSTONE, 2010; STROEH, 2008).

O glutamato tem sua ação na membrana pós-sináptica, na qual encontram-se os receptores específicos para este aminoácido, que são classificados de acordo com suas características farmacológicas e moleculares em metabotrópicos (mGluRs) e ionotrópicos (iGluRs). Existem três tipos de receptores (iGluRs) identificados farmacologicamente por afinidades com agonistas sintéticos: os receptores de N-metil-D-aspartato (NMDA), os receptores alfa-amino-3-hidróxi-metilisoxazole-propionato (Ampa) e os receptores de cainato (KA) (POPESCU, 2005). 
Quando o glutamato se liga aos domínios extracelulares de subunidades iGluR, toda a proteína sofre alterações de conformação para permitir o fluxo de cátions através da membrana plasmática, o que geralmente leva à despolarização da célula pós-sináptica. No ponto de vista fisiológico, os receptores Ampa e KA estão relacionados à transmissão sináptica rápida no $\mathrm{SNC}$ e são caracterizadas pelas rápidas cinéticas de ativação e desativação (STROEH, 2008; FEATHERSTONE, 2010).

Os receptores de NMDA são formados pelas subunidades de NR1 e NR2 (NR2A, NR2B, NR2C ou NR2D), estes com funções de ancoragem para os receptores na proteína PSD-95, bem como na sua interação com a proteína nNos e com a molécula de glutamato. A ativação desses receptores permite um alto influxo de Ca2+ para o interior das células, com seu potencial de repouso sendo mantido pelas concentrações extracelulares de magnésio $(\mathrm{Mg} 2+)$. Estes canais ligados a receptores NMDA tendem a permanecer abertos por mais tempo do que canais de receptores Ampa ou do tipo KA, justificando o alto fluxo de cálcio. Assim, a ativação do receptor NMDA pode iniciar cascatas de sinalização intracelular dependente de cálcio que leva à alteração na expressão gênica e na força sináptica manifestando-se, por exemplo, na aprendizagem e formação da memória (POPESCU, 2005; FEATHERSTONE, 2010).

Os receptores Ampa, com as suas subunidades GluR1, GluR2, GluR3 e GlurR4, permeáveis aos íons sódio $(\mathrm{Na}+)$ ou $\mathrm{Ca} 2+$ (na ausência da subunidade GluR2) geram um potencial excitatório rápido e consequentemente rápida dessensibilização do receptor. O receptor de KA, com suas subunidades GluR5, GluR6, GluR7, KA1 e KA2 diferenciam-se dos receptores Ampa principalmente pela condutância e desativação mais lentas. Estes receptores são encontrados em todo o encéfalo, sendo densamente localizados no córtex e hipocampo (BLOSS; HUNTER; GERALD, 2010).

Um potencial de ação pós-sináptico excitatório é gerado quando há liberação de glutamato das vesículas sinápticas, que por sua vez ativam inicialmente os receptores Ampa. A ligação do glutamato nos receptores Ampa controlam a entrada de $\mathrm{Na}+$ para o interior do neurônio, despolarizando-o, permitindo a liberação do $\mathrm{Mg} 2+$ e o desbloqueio de receptores NMDA. Uma vez que o receptor NMDA esteja desbloqueado, a união de glutamato e de seus coagonistas (D-serina e glicina) a este receptor permite a entrada de $\mathrm{Ca} 2+$ para dentro do neurônio. Deste modo, a disponibilidade de glicina na fenda sináptica, determinada pela sua liberação ou captação, pode modelar o equilíbrio de ativação de receptores de NMDA, o qual é controlado por transportadores específicos que mantêm os níveis de coagonista abaixo dos níveis de saturação (PINTO; RESENDE, 2014).

A captação do glutamato ocorre quando um transportador de aminoácidos excitatórios EAAT capta uma molécula de glutamato e três de $\mathrm{Na}+$, trocando-as por uma molécula de $\mathrm{K}+$, sendo este mecanismo dependente da atividade de $\mathrm{Na}+/ \mathrm{K}+$ ATPase, que mantém o gradiente de concentração de $\mathrm{Na}+$. A retirada do glutamato da sinapse por seus transportadores é fundamental para que ocorra o mecanismo da neurotransmissão excitatória normal, bem como a prevenção contra a toxicidade do glutamato (PINTO; RESENDE, 2014).

Quando não há a recaptação deste aminoácido, o glutamato torna-se tóxico, mostrando-se capaz de induzir doenças neurodegenerativas quando presente em altas concentrações, como esclerose lateral amiotrófica, DH, gerando o processo de excitotoxicidade, este também relacionado com doenças isquêmicas, doenças neurodegenerativas agudas e crônicas como epilepsia, hipóxia, anóxia, traumatismo craniano, mal de Alzheimer, infecções causados pelo vírus HIV, encefalopatia hepática e doenças genéticas como hemocisteinúria, hiperprolinemia e hiperamonemia (JIANG; AMARA, 2011; TAVARES, 2005; YERNOOL et al., 2004). 


\section{Neuropatologia glutamatérgica}

A hipótese da excitotoxicidade na DH iniciou com diferentes estudos mostrando que a administração de glutamato ou ácido caínico em ratos causava dano neuronal semelhante ao observado na patologia (BEAL et al., 1986; COYLE; SCHWARCZ, 1976). Essa hipótese foi confirmada posteriormente por pesquisas que relatava que a excitotoxicidade glutamatérgica é aumentada em modelos animais transgênicos nesta patologia (HODGSON et al., 1999; LEVINE et al., 1999). Os resultados sugeriam uma hiperestimulação de receptores NDMA que poderiam desempenhar um papel significativo na patogênese da DH.

A remoção do glutamato na fenda sináptica também pode contribuir de maneira expressiva para aumentar o dano excitotóxico na DH. Estudos em modelos animais transgênicos da doença (R6/2 e R6/1) demonstraram comprometimento na regulação do transportadores de glutamato 1 (GLT1) e transportador de glutamato e aspartato (Glast), juntamente com os baixos níveis de carreadores de aminoácidos excitatórios do subtipo 1 (EAAC1), resultando em uma diminuição da captação de glutamato no estriado desses animais (BEHRENS et al., 2002; LIEVENS et al., 2001; SHIN et al., 2005). Alterações na captação de glutamato também foram observadas em encéfalos post mortem de pacientes com DH (ARZBERGER et al., 1997; HASSEL et al., 2008). Assim sendo, os neurônios do terço médio da coluna espinhal podem ser especialmente susceptíveis ao glutamato aumentado devido a uma combinação de receptores NMDA abundante, baixos níveis de expressão EAAC1, e os baixos níveis de transportadores de glutamato na superfície celular da glia, resultando na excitotoxicidade (SHELDON; ROBINSON, 2007).

Os receptores que estão comumente envolvidos neste processo de excitotoxicidade são principalmente os do tipo NMDA, porém os receptores Ampa/KA também são ativados. Nos receptores NMDA quando há presença da proteína mutante promove a inibição da interação da proteína huntingtina normal com a proteína póssináptica PSD-95, (responsável por regular a atividade dos receptores NMDA), causando um aumento na sensibilidade desses receptores. Outras pesquisas também relatam um aumento nos níveis de metabólitos das vias das quinureninas, como o ácido quinolínico, que é um agonista do receptor glutamatérgico NMDA em encéfalos post mortem de pacientes com DH (GUIDETTI et al., 2004; ZUCKER et al., 2005). Já com os receptores Ampa/KA, promovem o influxo de $\mathrm{Ca} 2+, \mathrm{Na}+, \mathrm{Cl}-\mathrm{e} \mathrm{H} 2 \mathrm{O}$ por meio do gradiente osmótico, gerando edema, lise celular e consequentemente maior liberação de glutamato, que por sua vez ocasiona a morte celular por excitotoxicidade dando sequência a um ciclo de degeneração (PAPOUIN et al., 2012; SZYDLOWSKA; TYMIANSKI, 2010).

O corpo estriado do encéfalo recebe uma carga excitatória glutamatérgica de todo o córtex cerebral. A maioria dos neurônios GABAérgicos apresenta uma expansão elevada do receptor NMDA, bem como do receptor mGluR5, o qual potencializa as respostas dos receptores NMDA, contribuindo para o processo excitotóxico. Após o processamento da ativação crônica dos receptores NMDA, a concentração intracelular de Ca2+ aumenta, podendo conduzir à disfunção mitocondrial e à produção de ROS (espécies reativas de oxigênio) e de RNS (espécies reativas de nitrogênio), a ativação de proteases dependentes de Ca2+ (calpaínas), e a indução do processo apoptótico. Este conjunto de eventos contribui para a neurodegeneração progressiva observada no estriado dos indivíduos com a DH (GIL-MOHAPEL; REGO, 2011; REGO; OLIVEIRA, 2003).

A liberação exacerbada de glutamato gera um grande influxo de $\mathrm{Ca} 2+$ através do receptor de NMDA. O aumento exacerbado de $\mathrm{Ca} 2+$ dentro da célula gera acúmulo na mitocôndria, o que pode desencadear aumento da produção de ROS e levar as células à morte por apoptose. A estimulação exacerbada destes neurônios 
também desencadeia a exocitose de mais neurotransmissores, que por sua vez ampliam o fenômeno de excitotoxicidade contribuindo com a progressiva neurodegeneração do estriado (PINTO; RESENDE, 2014).

\section{CONCLUSÃO}

A proteína Huntingtina promove uma série de alterações, desde a superestimulação dos receptores NMDA até o comprometimento na regulação dos transportadores de glutamato GLT1, Glast e baixos níveis de EAAC1, desta forma conduzindo ao processo de neurodegeneração por meio da excitotoxicidade pelos níveis aumentados de glutamato.

Nesse sentido, existe uma necessidade de realizar uma atuação mais direcionada aos níveis da fisiopatologia da DH, a fim de adquirir novos conhecimentos específicos no que diz respeito a mecanismos de neurodegeneração, sobretudo a excitotoxicidade pelo glutamato. Isso poderá permitir desenvolver uma melhor compreensão e elucidação da fisiopatogênese, além de poder realizar uma combinação de estudos, pesquisas e resultados, para formular estratégias terapêuticas eficazes no tratamento desta doença, ou até mesmo abordagens terapêuticas neuroprotetoras e neurorregeneradoras, isto é, medidas que atuam na regressão e/ou inclusive na prevenção desta doença.

\section{REFERÊNCIAS}

ARZBERGER, T. et al. A. Changes of NMDA receptor subunit (NR1, NR2B) and glutamate transporter (GLT1) mRNA expression in Huntington's disease--an in situ hybridization study. J. Neuropathol. Exp. Neurol., 56(4): 440-454, 1997.

BEAL, M. F. et al. Replication of the neurochemical characteristics of Huntington's disease by quinolinic acid. Nature, 321(6066): $168-171,1986$.

BEHRENS, P. F. et al. Impaired glutamate transport and glutamate-glutamine cycling: downstream effects of the Huntington mutation. Brain, 125(8): 1.908-1.922, 2002.

BLOSS, E.B.; HUNTER, R. G.; GERALD, L. Hippocampal Kainate Receptors. Vitamins \& Hormones, v. 82, p. 167-184, 2010.

CORONA, J. C.; TAPIA, R. Mecanismos de Neurodegeneración. Mensaje Bioquímico. 29: 17-28, 2005.

COYLE, J. T.; SCHWARCZ, R. Lesion of striatal neurones with kainic acid provides a model for Huntington's chorea. Nature, 263(5574): 244-246, 1976.

FEATHERSTONE, D. E. Intercellular Glutamate Signaling in the Nervous System and Beyond. ACS Chem Neurosci, 1: 4-12, 2010.

GIL-MOHAPEL, J. M.; REGO, A. C. Doença de Huntington: uma revisão dos aspectos fisiopatológicos. Rev. Neurocien., 19(4):724$734,2011$.

GUIDETTI, P. et al. Neostriatal and cortical quinolinate levels are increased in early grade Huntington's disease. Neurobiol. Dis., 17(3): 455-461, 2004.

GREWER, C.; RAUEN, T. Electrogenic Glutamate Transporters in the CNS: Molecular Mechanism, Pre-steady-state Kinetics, and their Impact on Synaptic Signaling. J. Membr. Biol., 203(1):1-20, 2005.

HASSEL, B. et al. Glutamate uptake is reduced in prefrontal cortex in Huntington's disease. Neurochem. Res., 33(2): 232-237, 2008. 
HODGSON, J. G. et al. A YAC mouse model for Huntington's disease with full-length mutant huntingtin, cytoplasmic toxicity, and selective striatal neurodegeneration. Neuron, 23(1): 181-192, 1999.

JIANG, J.; AMARA, S. G. New views of glutamate transporter structure and function: Advances and challenges. Neuropharmacology, v. 60, n. 1, p. 172-181, 2011.

LEVINE, M. S. et al. Enhanced sensitivity to N-methyl-D-aspartate receptor activation in transgenic and knockin mouse models of Huntington's disease. J. Neurosci. Res., 58(4): 515-532, 1999.

LIEVENS, J. C. et al. Impaired glutamate uptake in the R6 Huntington's disease transgenic mice. Neurobiol. Dis., 8(5): 807-821, 2001.

PAPOUIN, T. et al. Synaptic and Extrasynaptic NMDA Receptors Are Gated by Different Endogenous Coagonists. Cell, v. 150, n. 3 , p. 633-646, 2012.

PINTO, M. C. X.; RESENDE, R. R. Excitotoxicidade e doenças neurológicas. Nanocell, v. 2, n. 4, 2014.

POPESCU, G. Mechanism-based targeting of NMDA receptor functions. Cellular and Molecular Life Sciences, v. 62, n. 18, p. 2.100$2.111,2005$.

REGO, A. C.; OLIVEIRA, C. R. Mitochondrial dysfunction and reactive oxygen species in excitotoxicity and apoptosis: implications for the pathogenesis of neurodegenerative diseases. Neurochem. Res., 28:1.563-1.574, 2003.

RIBEIRO, M. J. do C. Oxidative stress in Huntington's disease knock-in striatal cells. 2014. Tese (Doutoramento) - Coimbra. Disponível em: <http://hdl.handle.net/10316/25216>.

SHELDON, A. L.; ROBINSON, M. B. The Role of Glutamate Transporters in Neurodegenerative Diseases and Potential Opportunities for Intervention. Neurochem. Int., 51: 333-335, 2007.

SHIN, J. Y. et al. Expression of mutant huntingtin in glial cells contributes to neuronal excitotoxicity. J. Cell Biol, 171(6): 1.001$1.012,2005$.

STROEH, E. Estudo do inibidor da 3-Hidróxi 3-Metilglutaril-Coenzima A Redutase (Atorvastatina) na Transmissão e Toxicidade Glutamatérgica. 2008. 53 p. Trabalho (Monografia) - UFSC, Florianópolis, 2008.

SZYDLOWSKA, K.; TYMIANSKI, M. Calcium, ischemia and excitotoxicity. Cell Calcium, v. 47, n. 2, p. 122-129, 2010.

TAVARES, R. G. Modulação do sistema glutamatérgico: estudo dos efeitos do ácido quinolínico e dos derivados de guanina. 2005, 103 p. Tese (Doutorado) - UFRGS, Porto Alegre, 2005.

VALLI, L. G.; SOBRINHO, J. A. Mecanismo de ação do glutamato no sistema nervoso central e a relação com doenças neurodegenerativas. Revista Brasileira de Neurologia e Psiquiatria, 18 (1):58-67, 2014.

ZUCKER, B. et al. Transcriptional dysregulation in striatal projection- and interneurons in a mouse model of Huntington's disease: neuronal selectivity and potential neuroprotective role of HAP1. Hum. Mol. Genet., 14(2): 179-189, 2005.

YERNOOL, D. et al. Structure of a glutamate transporter homologue from Pyrococcus horikoshii. Nature, 481:811-818, 2004.

WALKER, F. O. Huntington's disease. Lancet, 369: 218-228, 20 jan. 2007. 